$12-2008$

\title{
Fixing the Leaky Pipe: Increasing Recruitment of Underrepresented Groups in Ecology
}

Brian L. Bingham

Western Washington University, brian.bingham@wwu.edu

Lisette E. Torres

Miami University

Follow this and additional works at: https://cedar.wwu.edu/esci_facpubs

Part of the Environmental Sciences Commons

\section{Recommended Citation}

Bingham, Brian L. and Torres, Lisette E., "Fixing the Leaky Pipe: Increasing Recruitment of Underrepresented Groups in Ecology" (2008). Environmental Sciences Faculty and Staff Publications. 4.

https://cedar.wwu.edu/esci_facpubs/4 


\section{Fixing the leaky pipe: increasing recruitment of underrepresented groups in ecology}

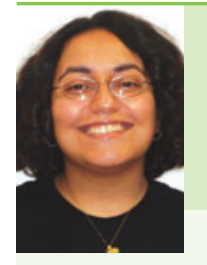

\author{
Lisette E Torres \\ Department of Zoology, \\ Miami University, Oxford, $\mathrm{OH}$ \\ (torresle@muohio.edu)
}

I would describe my graduate career in ecology as "serendipitous". As a daughter of Latino parents who grew up in challenging environments with limited access to education, I was lucky to graduate from college, let alone pursue a $\mathrm{PhD}$. I was also fortunate to meet a mentor who introduced me to ecology and graduate school. Unfortunately, many students from underrepresented groups lack adequate opportunities and mentorship as they head through the "pipeline" to graduate school. Despite the need for unique perspectives in collaborative scientific research, ethnic minority students continue to "leak" from the system. According to demographic projections, over $50 \%$ of the US population will be composed of individuals from underrepresented groups by the year 2050 (US Department of Commerce 1996). At present, however, these groups constitute only $6.5 \%$ of students enrolled in higher degree programs in ecology (NSF 2007). What can we do to remedy this? Exposure, opportunity, and access appear to be key. Here, I present some points for consideration for academic professionals (including educators, administrators, and program managers), based on the first-hand experiences of successful minority scientists I have interviewed or who have published on the subject.

Introduce ecology early and supply access to research and career opportunities. It is important to publicize research, internship, and graduate program opportunities and provide financial support. The Ecological Society of America's (ESA's) Strategies for Ecology Education, Development, and Sustainability (SEEDS) program has effectively introduced minority scientists to ecology by providing fellowships and field trips, as well as travel awards to ESA's annual meetings (www.esa.org/seeds/).

Create "bridge" programs that facilitate the transition of minority students from one level of academia to the next. Summer courses, orientation programs, internships, research experiences, and cultural events all teach students about the academic and social expectations of universities. For example, the Meyerhoff Scholars Program at the University of Maryland (UMD) has offered scholarships, summer bridge programs, and internships, as well as engaged students' families, and provided faculty and peer mentoring in an effort to recruit and retain minorities in science. As a result, minority participation in the sciences at UMD has increased 18\%; in addition, UMD has recently introduced a graduate fellows program (Summers and Hrabowski 2006; WebTables 1 and 2).

Build a sense of community through the creation of outreach programs or groups dedicated to learning. Community involvement is essential in reducing isolation and creating a nurturing environment. Greater communication and trust will attract new students, helping them to adjust and giving current graduate students a sense of belonging. To cultivate a feeling of community, consider establishing cohorts or shared learning events, where students at different stages in their academic careers can encourage one another (Cuker 2006; WebTables 1 and 2). Student involvement in community outreach is another great strategy; for instance, students in the Multicultural Initiative in the Marine Sciences: Undergraduate Participation (MIMSUP) program at Western Washington University teach marine science at public schools. By combining outreach with financial support, mentoring, and research experience, $65 \%$ of MIMSUP alumni enroll in graduate and professional degree programs (www.wwu.edu/mimsup/).

Foster supportive, personal mentor-mentee relationships. Many students feel that mentors are vital to academic success because they help their protégés keep things in perspective; it is therefore important that mentors have high expectations of their students while providing them with enough support to reach their goals. Mentors should also emphasize a student's achievements and encourage their participation in minority programs (Cuker 2006). The Minorities Striving and Pursuing Higher Degrees of Success in Earth System Science (MSPHDS; www.msphds.org/) program at the University of South Florida is a notable model of how having the right mentor(s), attending professional development workshops, and networking at conferences can make a real difference. One of the greatest strengths of this program is student engagement in one-on-one interactions with multiple mentors.

Incorporate multiculturalism, innovative teaching strategies, and professional development within curricula and departments (Rogers and Molina 2006). Minorities face distinct cultural and social challenges that can affect their chances of success. Creating a safe place for the discussion of underrepresentation in the sciences is therefore important (eg coursework or seminars that revolve around papers by women ecologists or topics such as environmental justice). Similarly, curricula that include inquiry-based techniques, critical thinking, real-world applications, and interdisciplinary approaches will keep students - regardless of their backgrounds - interested in ecology. (For examples of creative curriculum changes, see www.esa.org/seeds/pdf/ 
SEEDSreport.pdf.) Workshops on balancing an academic career and family, salary negotiation, grant and technical writing, mentoring, and academic socialization (WebTables 1 and 2) will be useful to most graduate students.

Develop a critical mass of underrepresented groups ( 20\% of enrolled students within a program; Rogers and Molina 2006; WebTable 1). Linkages with minority programs (eg SEEDS, MSPHDS), historical institutions of color, schools with high minority enrollment, funding institutions, and the scientific community (Cuker 2006) will help in the recruitment of minority students. By working with Historically Black Colleges and Universities, the United Negro College Fund, and the Institute of Ecosystem Studies, SEEDS has increased student involvement in ecological research, internships, and attendance at scientific meetings (www.esa. org/seeds/pdf/SEEDSreport.pdf).

Evaluate and document successes to attract students from underrepresented groups and support funding requests (Cuker

\section{Faculty response}

Brian Bingham
Professor, Department of Environmental
Sciences, Western Washington University,
Bellingham, WA
(brian.bingham@wwu.edu)

Students from underrepresented groups face unique challenges; recognizing those challenges is a first step to addressing them. Faculty who understand the hurdles these students face can more effectively draw talented individuals into the field and help them succeed once they get there.

Recruitment is the vital first step to solving the pipeline problem. A spacious pipeline - flush with strong programs, excellent funding, and willing mentors - will accomplish little if the spigot is working at a trickle. In my experience, successful recruitment requires considerable effort. Blanket announcements, bulletin board flyers, and mass e-mails do a poor job of attracting students who (1) are inundated with information and simply don't pick out the relevant opportunities or (2) lack the confidence to apply for something they feel is intended for somebody else. Effective recruiting requires individual effort. Committed faculty, aware of the students around them, can make a big difference; we can consciously watch for opportunities, reach out, pull a student in, and ask, "Have you seen this? Why don't you apply?" Sometimes, that is all it takes.

Faculty can help with recruiting, but students have a critical role, too. Those who have found their way into the system have a responsibility to reach back and pull younger students along. They can build the networks. As faculty, we need to encourage and facilitate such efforts.

Once in the pipeline, a student may find it a bewildering place. Misunderstandings can arise simply because students don't recognize how the system works. For example, they may not understand the career goals of their adviser
2006). More research and program assessments on minority recruitment and retention are needed in the sciences. Successful strategies should be identified, implemented, and reassessed, using clear goals and objectives (WebTables 1 and 2). Successful strategies for the recruitment and retention of minorities can result in positive feedback that will benefit everyone involved. We can patch the leaky pipeline by introducing minority students to ecology, giving them the opportunity to be a part of the scientific community, and providing access to the resources they will need to become successful scientists.

\section{Acknowledgements}

I thank CE Williamson and C Martinez for feedback on drafts of this manuscript, as well as J Strickland, L Alade, L Vigue-Miranda, and the members of the MSPHDS program for sharing their experiences with me.

or how their own performance impacts those goals. Clearly defining expectations on the part of the student and the adviser sets the stage for a successful partnership.

Lisette lists a variety of activities that can enhance students' retention. Some demand considerable investment of money or time, both of which are in short supply for overburdened faculty. Fortunately, we do not all have to develop elaborate programs. Even small efforts can yield large returns, if enough of us actively participate. Each of us can discuss opportunities with individual students, encouraging them to apply. We can create targeted e-mail distribution lists so students know what is available. We can clarify expectations with our students, teaching them about our profession. We can support and foster outreach efforts. We can mentor.

Recruitment and retention of students from underrepresented groups are critical to maintaining and enhancing the intellectual health of our field. There is a pool of talent we have barely begun to tap. Through even relatively small steps, the collective efforts of faculty around the country can substantially strengthen and enlarge the pipeline, thereby embracing the contributions of a remarkable group of individuals.

\section{References}

Cuker BE. 2006. Programmatic approaches to building diversity in the ocean sciences. Mar Technol Soc J 39: 13-16.

NSF (National Science Foundation). 2007. Graduate students and postdoctorates in science and engineering: fall 2005. Arlington, VA: NSF. NSF 07-321.

Rogers MR and Molina LE. 2006. Exemplary efforts in psychology to recruit and retain graduate students of color. Am Psychol 61: 143-56.

Summers MF and Hrabowski III FA. 2006. Preparing minority scientists and engineers. Science 311: 1870-71.

US Department of Commerce. 1996. Current population reports: population projections of the United States by age, sex, race, and Hispanic origin: 1995 to 2050. Washington, DC: US Department of Commerce. 